\title{
A RETROSPECTIVE STUDY OF ADVERSE EVENTS IN BLOOD DONORS FROM NAVI MUMBAI.
}

Seema Gupta, Aruna Madan, Reeta Dhar, D.B. Borkar

1. Assistant Professor. Department of Pathology, MGM Medical College, Kamothe, Navi Mumbai.

2. Assistant Professor. Department of Pathology, MGM Medical College, Kamothe, Navi Mumbai.

3. Professor \& HOD. Department of Pathology, MGM Medical College, Kamothe, Navi Mumbai.

4. Professor. Department of Pathology, MGM Medical College, Kamothe, Navi Mumbai.

\section{CORRESPONDING AUTHOR:}

Dr. Seema A. Gupta,

502, Westend Apartment, Sector-19A,

Nerul, Navi Mumbai-400706.

E-mail: seemaagupta@gmail.com

Ph: 00919819131787

ABSTRACT: BACKGROUND: The safety and sufficiency of blood supply is dependent on the altruism of healthy donors, to provide blood. These donors get exposed to potential risk of discomfort, complications, and rarely injury from the collection procedure. All medical procedures including blood donation carry some risk of adverse events (AE). Although blood donation is generally safe, approximately of $2-6 \%$ of donors experience complications, mostly mild, that resolve promptly but are still unpleasant for donors, and blood services have an obligation to minimize them. The aim of this study was to estimate the frequency and severity of AE's occurring in whole blood donors, especially in outdoor camps, and to suggest measures to minimize them._MATERIALS AND METHODS: This is a five year retrospective study on whole blood donors (2008-2012). Our blood collection is mainly in camps by voluntary blood donors. Donations in camps: voluntary- 8992(81.2\%). Donations in blood bank: voluntary 831(7.53\%), replacement 1211(10.97\%). RESULTS: Overall 258 adverse events occurred in a total of 11034 donors, resulting in an adverse event rate of $2.33 \%$. Most common AE was presyncopal or vasovagal reaction (72.86\%). Syncopal minor reactions associated with transient loss of consciousness comprised $14.3 \%$. Severe AE's formed a very small fraction accounting for 1.16\%. CONCLUSION: AE analysis helps in identifying the donors at risk and adopting environmentally appropriate measures to reduce risk and improve donor satisfaction.

KEY WORDS: voluntary blood donation, outdoor camps, adverse events, vasovagal reactions.

INTRODUCTION: All medical procedures carry some risk of adverse events (AE) and blood donation is no exception. After proper donor selection as per the laid down criteria, blood donation is a relatively safe procedure. However, occasionally AE's do occur which are usually mild, but can be severe. Donor complications are an important problem not only for the donors, but also for transfusion medicine in general, as some complications may negatively affect donor recruitment and retention ${ }^{1}$. Adverse events have a negative effect on donor health, donor satisfaction and blood donor return rate (BDRR)2. AEs result in disrupted work flow at blood donor centres, impact on customer service to other donors, and also result in loss of/wastage of blood products. Various studies have quoted an AE of 2-6\% in donors but only $0.08-0.3 \%$ have a syncopal reaction where there is loss of consciousness ${ }^{3,4,5}$. In order to have an adequate and regular supply of blood it is not only important to recruit new donors but also to retain them as repeat donors. 
AIMS \& OBJECTIVES: To estimate the frequency and severity of AE's occurring in whole blood donors especially in outdoor camps and to suggest measures to minimize them

INCLUSION EXCLUSION CRITERIA: Data was obtained from our records of donor collection, in camps and in MGM blood bank premises, during the period of January 2008 to December2012. Our minimum requirement for a blood donor is: age between 18 to 60 years, haemoglobin $>12.5 \mathrm{gm} \%$, weight $>45 \mathrm{~kg}$ for $350 \mathrm{ml} \&>55 \mathrm{~kg}$ for $450 \mathrm{ml}$. Donors not meeting the minimum requirement and other criteria as per guidelines in Drugs \& Cosmetics Act, Ministry of Health \& Family Welfare, Government of India ${ }^{6}$, were not bled.

No professional donors were bled as per our policy.

MATERIALS AND METHODS: This is a 5 year retrospective study from January 2008 to December 2012 of MGM Medical College Blood Bank, Navi Mumbai. The population analysed in this study consisted of 11,034 donations of which 9,823 (89.02\%) were voluntary and 1,211 $(10.97 \%)$ were replacement. They were selected as per guidelines laid down in Drugs \& Cosmetics Act, Ministry of Health \& Family Welfare, Government of India ${ }^{6}$. Blood was collected using a 16 gauge needle from the antecubital vein under proper aseptic technique. $350 \mathrm{ml}$ of blood was collected from donors weighing between 45 - $55 \mathrm{~kg}$ and $450 \mathrm{ml}$ from those weighing more than $55 \mathrm{~kg}$. Minimum haemoglobin level was $12.5 \mathrm{~g} \%$. Haemoglobin screening was done by copper sulphate method and borderline cases were confirmed with Hemocue $₫$ AB, Sweden.

Pre-donation medical examination was done in all donors and those who did not confirm were excluded. Donors were closely observed during and after donation for any AE. Total turnaround time was about 45 minutes in donors with no AE's. Turnaround time was increased depending upon type and severity of $\mathrm{AE}$.

The classification scheme employed for recording the AE's was, as suggested by the American Red Cross Hemovigilance Program that classifies complications into systemic and local. Depending on the severity, some categories have been further divided into minor and major7. Pre-syncopal or vasovagal reactions include pallor, sweating or light headedness, without loss of consciousness (LOC). In syncopal reaction characterized as minor, LOC is transient, lasting for less than one minute. Prolonged LOC lasting for more than one minute or complicated by loss of bowel/ bladder control, seizures or convulsions, is labelled as a major syncopal reaction. Local AE's include haematoma, which can be small $(<2.2$ in.) or large $(>2.2$ in.), arterial puncture (major category), bruises, allergic reactions, nerve irritation etc.

This study has been approved by the ethical committee of MGM University of Health Sciences.

Statistical analysis was done wherever necessary.

RESULTS: In the 5 year study period from January 2008 - December 2012, 11034 whole blood donations were collected, of which 9823 (89.02\%) were voluntary and 1211 (10.98\%) were replacement donors. Most of the voluntary donations were collected in the camps 8992 $(81.49 \%)$ as against the replacement donors 1211 (10.98\%) collected in the blood bank. Majority of the donors were males 9742 (88.29\%) and proportion of the female donors 1292 $(11.71 \%)$ was significantly lower. First time donors were $8792(79.7 \%)$ and repeat donors were 2242 (20.3\%). Blood collection details are presented in Table 1.

Adverse events were recorded in 258 donors giving an overall incidence of $2.33 \%$. Of the $258 \mathrm{AE}$ 's, 188 were pre-syncopal i.e. mild vasovagal reactions, accounting for $72.86 \%$ of all AE's and affecting $1.7 \%$ of all donors. Agitation, pallor and sweating are the harbingers of 
vasovagal reactions and associated with pre-donation anxiety. These reactions were seen more often in first time donors 8792 (79.7\%) and in female gender 1292 (11.71\%). Next in frequency, were syncopal minor reactions $37(0.33 \%)$ characterized by transient loss of consciousness, lasting less than one minute. Haematoma formation was observed in $24(9.3 \%)$. Other minor reactions $6(0.08 \%)$ included tingling, numbness, soreness of arm, local allergy, etc. There were $3(0.02 \%)$ major reactions one each of convulsion, loss of bladder sphincter control and accidental arterial puncture. These formed a very small fraction of the AE's accounting for only $1.16 \%$, affecting $0.02 \%$ of the donors, and none necessitating hospitalization. The type and frequency of various adverse events occurring in the donor population is presented in Table 2.

DISCUSSION: The safety and sufficiency of blood supply is dependent on the altruism of healthy donors to provide blood7. These donors get exposed to potential risk of discomfort, complications and rarely injury from the collection procedure ${ }^{7}$. Although blood donation is generally considered a safe procedure, data reported in the medical literature about the frequency of adverse events during donation show a broad heterogeneity ${ }^{5,8,9}$. Approximately 2$6 \%$ of all presenting donors experience complications, mostly mild, that resolve promptly, but are still unpleasant for the donor, and blood services have an obligation to minimize them ${ }^{4}$ 8-15. The aim of this study was to estimate the frequency and severity of AE's occurring in whole blood donors, especially in outdoor camps, and to suggest measures to minimize them.

11034 units of whole blood donations were collected from $9823(89.02 \%)$ voluntary and $1211(10.98 \%)$ replacement donors. Voluntary donations collected in camps 8992(91.5\%) was significantly higher than in blood bank 831(8.4\%) $(\mathrm{P}<0.001)$. Male donors were 9742(88.29\%) \&female donors were 1292(11.71\%). Proportion of female donors was significantly higher in voluntary donors $1248(12.7 \%)$ as compared to replacement donors $44 / 1211(3.63 \%)(\mathrm{P}<0.001)$

AE's occurred in 258 donors accounting for $2.33 \%$. Similar AE rates have been reported by Agnihotri et al ${ }^{16}$ in their study in North India where blood was collected predominantly in camps. Lower AE rates $(0.6 \%)$ have been observed by Chintamani Pathak et al ${ }^{17}$ in a regional blood centre in India. Medical literature has reported prevalence rates varying from $8.9 \% 18$ to $11-21 \% 5$.

Out of 258 AEs, 217(81.4\%) occurred in camps and 41(18.65) in blood bank premises, the difference was not found to be statistically significant $(\mathrm{p}=0.27)$

Pre-syncopal reactions formed the bulk of the observed AE's accounting for $72.86 \%$ $(188 / 258)$. This is consistent with other studies ${ }^{17}, 19$ but slightly higher than that reported by Agnihotri et al $^{16}$. In donors who developed a vasovagal reaction, the blood collection was immediately discontinued and the donor was put in antishock position with monitoring of pulse and BP \& supplemented with oral glucose water. These donors were kept under observation for about 30 minutes on an average. It is important to identify early signs of vasovagal reaction i.e. agitation, pallor and sweating so that swift action can be taken and further progress can be halted.

We collect blood in outdoor camps in and around Navi Mumbai which is hot and humid during most of the months in the year. More AE's were observed in the afternoons when there was clustering and crowding of donors. Hence we insisted on pre-donation fluid intake (Amla drink) in addition to post donation refreshment. This is in agreement with the recommendations given by Marco Bani et al ${ }^{20}$ advising strategies to reduce adverse reactions 
viz. the consumption of fluids (water/ coffee) about half an hour before donation, audiovisual material and social support.

Only 24 cases of haematoma formation were recorded, affecting $0.21 \%$ of donor population. As reported in the literature incidence of haematoma formation varies from $12.3 \%{ }^{17}$ to $35 \%{ }^{16}$ and comparatively ours at $0.21 \%$ is very low. In Newman's study incidence of haematoma was more when phlebotomist was untrained, had poor technique or failed to select the best vein ${ }^{5}$.

Accidental arterial puncture $1(0.01 \%)$ is a very rare adverse event and is suggested by rapid filling ( $<3$ minutes) of the bag, pulsatile flow and bright red colour. Donors with arterial punctures do well if pressure is applied for an extended period of time, as in our case. Rarely, a pseudoaneurysm results, and this requires surgery. AV fistulas and compartment syndromes can also occur, but these are extremely rare; most experienced blood centre physicians have never observed a case ${ }^{5}$.

Like other authors $15,21,22$ we found a very low incidence of severe reactions $3(0.027 \%)$ with no episode requiring hospitalization of the donor.

CONCLUSION: AE analysis of our donors shows an overall similarity with other Indian studies. Most of our reactions are vasovagal, and incidence of our local reactions (haematoma) is very low $(0.07 \%)$. A brief comparison of AEs in different studies is presented in Table3.

We also assessed certain practices which would help in reducing AE's in donors. Special attention is paid to high risk donors i.e. young college going students who were first time donors and thin built. Anxious donors are made comfortable by engaging them in conversation in order to divert their attention. A friendly environment can do wonders for this group. Initial signs of vasovagal are identified at the earliest, and by putting the donor in Trendelenburg's position, further progress can be halted. Semi-sitting positions are avoided during donations and $350 \mathrm{ml}$ rather than $450 \mathrm{ml}$ is collected from females and young college going donors. In camps, where the premises are not air-conditioned, pre-donation refreshment drink is helpful.

Donor safety is of prime importance as donor reaction has a negative impact on the blood donor return rates (BDRR)2. This is especially important in the setting of predominantly voluntary collections (89.5\%) as we strive to achieve the National Blood policy of attaining $100 \%$ voluntary collection. Analysis of Adverse Events has led to improved vigilance by the staff leading to better management and better donor satisfaction.

\section{REFERENCES:}

1. France CR, France JL, Roussos M, Ditto B: Mild reactions to blood donation predict a decreased likelihood of donor return. Transfus Apher Sci 2004; 30:17-22

2. Newman BH, Newman DT, Ahmad R, Roth AJ. The effect of whole-blood donor adverse events on blood donor return rates. American Red cross blood Services, Southeastern Michigan Region, Michigan 48201, USA.

3. Lin JT, Ziegler DK, Lai CW, Bayer W. Convulsive syncope in blood donors. Ann Neurol. 1982;11:525-8.

4. Trouern-Trend JJ, Cable RG, Badon SJ, Newman BH, Popovsky MA. A case-controlled multicenter study of vasovagal reactions in blood donors: Influence of sex, age, donation status, weight, blood pressure, and pulse. Transfusion.1999;39:316-20.

5. Newmann BH. Donor reactions and injuries from whole blood donation. Transf Med Rev. 1997;11:64-75.

6. Drugs and Cosmetics Act 1940.16th ed. Lucknow: Eastern Book Company; 2003. p. 279-303. 
7. Eder AF, Dy BA, Kennedy JA, et al. The American Red Cross Donor Hemovigilance Program, complications of donation. Transfusion. 2006;46:2037-42.

8. Kasprisin DO, Glynn SH, Taylor F, Miller KA. Moderate and severe reactions in blood donors. Transfusion. 1992;32:23-6.

9. Ogata $\mathrm{H}$, Iinuma $\mathrm{N}$, Nagashima $\mathrm{K}$, Akabane $\mathrm{T}$. Vasovagal reactions in blood donors. Transfusion. 1980;20:679-83.

10. Popovsky MA, Whitaker B, Arnold Nl. Severe outdoor allogenic and autologous blood donation: frequent characterization. Transfusion 1995;35:734-7

11. Shehata N,Kusano, Hannach B, Hume H, Reaction rates in allogenic donors.Tranfuse Med 2004;14:327-33.

12. Poles FC, BoycotTM,Syncope in blood donors.Lancet 1942;240: 531-5.

13. Tomasualo PA, Anderson AJ, Puluso MB, Gutschenritter MA, Aster RH. A study of critera for blood donor deferral. Transfusion. 1980 Sep-Oct;20(5):511-8.

14. Newman BH, Siegfried BA, Buchanan LA..Donor reactions among African- American and Caucansian first-time whole blood donors. Transfusion. 2005 Aug;45(8):1398-9.

15. Newman BH, Satz SL, Janowicz NM,SiegfriedBA.Donor reaction in high -school donors: the effects of sex, weight, and collection volume. Transfusion 2006;46:284-8

16. Agnihotri N, Marwaha N, Sharma RR. Analysis of Adverse Events and predisposing factors in voluntary and replacement whole blood donors: a study from north India. Asian J Transfus Sci 2012;6:155-160.

17. Chintamani Pathak, Meeenu Pujani, sangeeta Pahuja, Manjula Jain. Adverse reactions in whole blood donors: an Indian scenario. Blood Transfus 2011;9:46-9.

18. Boynton MH, Taylor ES. Complications arising in donors in a mass blood procurement project. Am J Med Sci. 1945;209:421-36.

19. Crocco I, Franchini M, Garozzo G, et al. Adverse reactions in blood and apheresis donors: experience of two Italian transfusion centres. Blood Transfus. 2009;7:35-8.

20. Marco Bani and Barbara Giussani.Gender differences in giving blood: A review of the literature.Blood Transfus.2010 October:8(4):278-287

21. Crocco A, D'Elia D. Adverse reactions during voluntary donation of blood and/or components. A statistical-epidemiological study. Blood Transfus. 2007;5:143-52.

22. Franchini M, Gandini G, Gandini AR, et al. Frequency of adverse events during blood and apheresis donations: a single center based study. Transfusionsmedizin. 2002;29:200-

Table1: Blood Collection Details (2008 - 2012)

\begin{tabular}{|c|c|c|}
\hline DONORS & COLLECTION IN CAMPS & COLLECTION IN BLOOD BANK \\
\hline VOLUNTARY & $8992(81.49)$ & $831(7.53)$ \\
\hline Males & $7927(71.84)$ & $648(5.8)$ \\
\hline Females & $1065(9.65)$ & $183(1.65)$ \\
\hline REPLACEMENT & - & $1211(10.97)$ \\
\hline Males & - & $1167(10.57)$ \\
\hline Females & - & $44(0.39)$ \\
\hline \hline Total & $\mathbf{8 9 9 2 ( 8 1 . 5 )}$ & $\mathbf{2 0 4 2 ( \mathbf { 1 8 . 5 } )}$ \\
\hline
\end{tabular}

Figures in parentheses indicate percentages. Percentages are out of total number of donors i.e. 11034 donors. 
Table 2: Type and Frequency of Adverse Events

\begin{tabular}{|c|c|c|}
\hline TYPE OF ADVERSE EVENTS & No OF DoNORS WITH AE & PERCENTAGE \\
\hline SYSTEMIC COMPLICATIONS & & \\
\hline Presyncopal & 188 & 1.7 \\
\hline Syncopal (minor) & 37 & 0.33 \\
\hline Syncopal(major) & 2 & 0.02 \\
\hline LOCAL CoMPLICATIONS & & \\
\hline Haematoma & 24 & 0.21 \\
\hline Arterial puncture & 1 & 0.01 \\
\hline Other minor reactions & 6 & 0.05 \\
\hline \hline Total & $\mathbf{2 5 8}$ & $\mathbf{2 . 3 3}$ \\
\hline
\end{tabular}

Table 3 : Comparison of AE's in various studies

\begin{tabular}{|c|c|c|c|c|c|}
\hline NAME OF STUDY & $\begin{array}{c}\text { TOTAL AE'S } \\
\text { (\%) }\end{array}$ & $\begin{array}{c}\text { TOTAL } \\
\text { DONORS } \\
\text { (WB) }\end{array}$ & $\begin{array}{c}\text { VASOVAGAL } \\
\text { AE's (\%) }\end{array}$ & $\begin{array}{c}\text { НЕМАТОМА } \\
(\%)\end{array}$ & $\begin{array}{c}\text { SEVERE AE's } \\
(\%)\end{array}$ \\
\hline Our study & $\begin{array}{c}258 / 11034 \\
(2.3)\end{array}$ & 11034 & $\begin{array}{c}188 / 11034 \\
(1.7)\end{array}$ & $\begin{array}{c}24 / 11034 \\
(0.21)\end{array}$ & $\begin{array}{c}3 / 11034 \\
(0.027)\end{array}$ \\
\hline Agnihotri et al. ${ }^{16}$ & $\begin{array}{c}948 / 37896 \\
(2.5)\end{array}$ & 37896 & $\begin{array}{c}602 / 37896 \\
(1.59)\end{array}$ & $\begin{array}{c}332 / \\
37896 \\
(0.88) \\
\end{array}$ & - \\
\hline $\begin{array}{l}\text { Chintamani et } \\
\text { al. }{ }^{17}\end{array}$ & $\begin{array}{c}113 / 19045 \\
(0.59)\end{array}$ & 19045 & $\begin{array}{c}79 / 19045 \\
(0.05)\end{array}$ & $\begin{array}{c}14 / 19045 \\
(0.07)\end{array}$ & $\begin{array}{c}1 / 19045 \\
(0.005)\end{array}$ \\
\hline Crocco A et al 21 . & $\begin{array}{c}63 / 4906 \\
(1.3)\end{array}$ & 4906 & $\begin{array}{c}59 / 4906 \\
(1.080)\end{array}$ & - & $\begin{array}{c}4 / 4906 \\
(0.2)\end{array}$ \\
\hline Crocco I. et al. ${ }^{19}$ & $\begin{array}{c}352 / \\
183855 \\
(0.19)\end{array}$ & 183855 & $\begin{array}{c}346 / \\
183855 \\
(0.2)\end{array}$ & - & $\begin{array}{c}6 / 183855 \\
(0.003)\end{array}$ \\
\hline
\end{tabular}

